\title{
Modelling Thomson Coils with Axis-symmetric Problems: Practical Accuracy Considerations
}

DOI:

10.1109/TEC.2017.2651979

\section{Document Version}

Accepted author manuscript

Link to publication record in Manchester Research Explorer

\section{Citation for published version (APA):}

Vilchis-Rodriguez, D., Shuttleworth, R., \& Barnes, M. (2017). Modelling Thomson Coils with Axis-symmetric Problems: Practical Accuracy Considerations. IEEE Transactions on Energy Conversion, 32(2), 629-639. https://doi.org/10.1109/TEC.2017.2651979

\section{Published in:}

IEEE Transactions on Energy Conversion

\section{Citing this paper}

Please note that where the full-text provided on Manchester Research Explorer is the Author Accepted Manuscript or Proof version this may differ from the final Published version. If citing, it is advised that you check and use the publisher's definitive version.

\section{General rights}

Copyright and moral rights for the publications made accessible in the Research Explorer are retained by the authors and/or other copyright owners and it is a condition of accessing publications that users recognise and abide by the legal requirements associated with these rights.

\section{Takedown policy}

If you believe that this document breaches copyright please refer to the University of Manchester's Takedown Procedures [http://man.ac.uk/04Y6Bo] or contact uml.scholarlycommunications@manchester.ac.uk providing relevant details, so we can investigate your claim.

\section{OPEN ACCESS}




\title{
Modelling Thomson Coils with Axis-symmetric Problems: Practical Accuracy Considerations
}

\author{
D.S. Vilchis-Rodriguez, Member, IEEE, R. Shuttleworth, Member, IEEE \\ and M. Barnes, Member, IEEE
}

\begin{abstract}
This paper assesses factors that impact the simulation accuracy of a 2D finite element (FE) transient axissymmetric model of a Thomson Coil actuator. 3D FE analysis (FEA) is used to show that geometric differences between a planar coil and the intrinsic assumptions of a 2D axial model may result in important differences in coil inductance. It is then shown that inductance and resistance compensation of the $2 \mathrm{D}$ model can be used to produce an accurate prediction of the TC performance. Detailed parameters of a prototype TC test system are used as inputs in the compensated 2D axial model and excellent agreement is observed between 2D FE simulations and experimental results. It is also shown that armature vibration modes explain the presence of apparent speed oscillations in the experimental results not present in numerical simulations. The compensated 2D axis-symmetric model shows good accuracy compared with experimental results for the investigated scenarios, even when armature flexing is considered.
\end{abstract}

Index Terms - High speed switches, HVDC breaker, magnetic repulsion, Thomson Coil, ultra-high speed actuator.

\section{INTRODUCTION}

$\mathrm{F}^{-1}$ OR applications that require ultra-fast actuation, the preferred actuator design is based on the Thomson Coil (TC) [1-5]. The TC comprises a planar coil and an electrically conductive disc armature, placed in close proximity and parallel to the coil, Fig. 1. In operation the coil is excited by a time varying current and produces a time varying magnetic field, inducing eddy currents in the disc armature. Due to the direction of the induced eddy currents, a repulsive magnetic force appears between coil and armature, enabling rapid armature reaction and high speed displacement. Given the relevance of the design in the operation of ultra-high speed mechanical switches, such as MV [1-4], HV DC breakers[5] and traction applications [6], considerable effort has been put into its modelling, design and optimization [6-16]. From the existing modelling tools, transient 2D FEA has been shown to provide accurate results for armature speeds around $10 \mathrm{~m} / \mathrm{s}$ $[14,15]$. However, in [15] predicted armature velocity was shown to diverge from measured values as armature velocity

This work was funded as part of the UK EPSRC, FCL/B: An Integrated VSC-HVDC Fault Current Limiter/Breaker project, EP/L021552/1.

D.S. Vilchis-Rodriguez, R. Shuttleworth and M. Barnes are with the Power \& Energy Division, School of Electrical and Electronic Engineering, The University of Manchester, Manchester M13 9PL, UK. (e-mail: Damian.Vilchis-Rodriguez@manchester.ac.uk). increased beyond $7 \mathrm{~m} / \mathrm{s}$. Speed oscillations in some experimental results were not present in the numerical simulation. It was argued in [15] that the differences in speed between simulations and experimental results were due to armature bending, not considered in the model. Given that a TC actuator is normally required to operate at high speed, an analysis of the factors that impact on FE simulation accuracy compared to measured values is necessary in order to reduce discrepancies.

Due to the TC actuator symmetry, a 2D axial model of the coil is generally considered to be a good approximation for $\mathrm{FE}$ modeling and analysis [14-16]. However, geometric differences between a 2D model and the physical planar coil and disc armature may give rise to disparities in inductance and resistance values, resulting in misleading results. For more accurate calculation of coil inductance and resistance a 3D FEA model should be used. However a full 3D FE transient simulation of a multi-physics system is taxing in terms of simulation time and computer resources. Therefore a $2 \mathrm{D}$ model is usually preferred for fast transient assessment, particularly at an early stage in the design process. In this paper a detailed analysis of the components present in a typical TC system is conducted. The parameters of a purpose built test-rig were used as inputs to a $2 \mathrm{D}$ FE axis-symmetric model implemented using COMSOL 5.2 multi-physics software. Measured inductance values predicted using alternative methods illustrate limitations to the capabilities of the 2D axis-symmetric FE model. In order to reduce error in the 2D model, a steady state 3D FEA model of the coil was used to calculate coil inductance and resistance. The 2D simulation (which predicts lower coil inductance and resistance values than the $3 \mathrm{D}$ model) was compensated accordingly by adding passive inductor and resistor components in series with its coil model to correct for differences. The effect of armature bending on the accuracy of the model predictions is also investigated. The compensated 2D FE axial model results exhibit excellent agreement with experimental measurements for the investigated scenarios.

\section{FE MODEL IMPLEMENTATION AND EXPERIMENTAL SET UP}

Figure 2 shows a schematic diagram of a typical TC test arrangement. During operation, the capacitor bank $\mathrm{CB}_{1}$ is charged to a predefined voltage level $\mathrm{V}_{0}$, and then isolated from the power supply by opening switch $\mathrm{S}_{1}$. To operate the actuator, thyristor $T_{1}$ is triggered to excite the spiral coil and 
initiate armature displacement. The thyristor conducts until the TC current falls below the thyristor holding current. Diode $\mathrm{D}_{1}$ protects the capacitor bank against reverse voltage. For accurate simulation of the system correct characterization of the capacitor bank, diode, thyristor, coil resistance, coil inductance and connection lead inductance and resistance is required. Although capacitors of the same rating and manufacturer were used during this research, these were found to have different capacitance values. Therefore in the simulations, each capacitor was modelled individually in terms of its capacitance and equivalent series resistance (ESR). In a TC actuator very high peak currents flow through the system components, therefore, the high temperature V-I characteristic of the diode and thyristor were used during simulations.

\section{A. Experimental test-rig}

A test-rig based on the system described above was constructed for model validation purposes. The planar coil comprises 28 turns of circular cross section $3 \mathrm{~mm}$ diameter, enamelled copper wire. The coil possesses an inner diameter of $4 \mathrm{~cm}$ and is embedded in a $25 \mathrm{~mm}$ Tufnol sheet and fixed with epoxy resin. The wire insulation thickness was measured as $0.055 \mathrm{~mm}$, therefore the separation gap between consecutive turns is assumed as $0.11 \mathrm{~mm}$. The capacitor bank comprises three parallel connected FELSIC 85/s electrolytic capacitors, each rated at $450 \mathrm{~V}, 8250 \mu \mathrm{F}$. A high power diode, type VISHAY VS-240U80D, was used for capacitor reverse voltage protection and a SEMIKRON SKKT 162/12E Thyristor to initiate capacitor bank discharge. The capacitance of each capacitor was measured and the ESR obtained from the manufacturer datasheet; maximum ESR value was used in the simulations. Connection lead resistance and inductance were measured using an Agilent 3442OA Micro Ohm Meter and an Agilent 4294A impedance analyzer, respectively. The circuit connections comprised several interconnected leads. Consequently the resistance and inductance may be slightly different when connected in the circuit, due to changes in contact resistance and geometry, respectively. Table I summarizes the geometric and electric parameters of the TC test rig and Fig. 3 shows a picture of the assembled test system. Coil lead outs, the short conductor segments at both ends of the spiral coil that are part of the coil wire but do not follow the planar spiral path (see Figs. 1-2), are considered separately to the connection leads values listed in Table I. The total length of the coil lead outs was measured as $47 \mathrm{~cm}$, equivalent to 1.13 $\mathrm{m} \Omega$, considering nominal conductor resistivity. Coil lead outs inductance was assumed negligible.
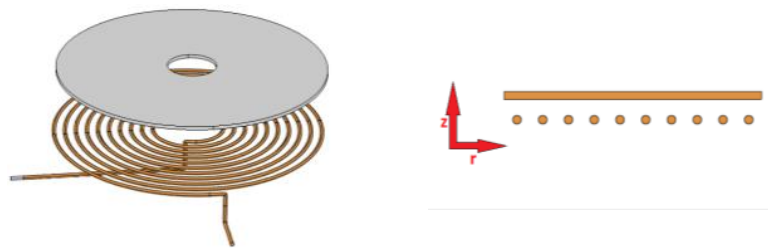

Fig. 1. TC 3D diagram (left) and 2D axis-symmetric representation (right).

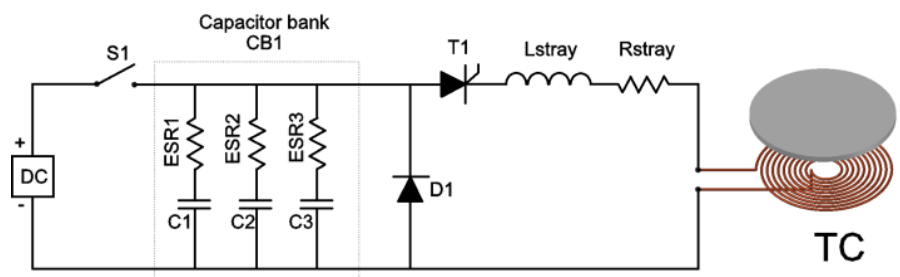

Fig. 2. Schematic diagram of a typical TC system TABLE I

TC TEST SYSTEM PARAMETERS

\begin{tabular}{|l|l|}
\hline Characteristic & Value \\
\hline Turn number & 28 \\
\hline Conductor diameter & $3 \mathrm{~mm}$ \\
\hline Insulation thickness & $0.055 \mathrm{~mm}$ \\
\hline Conductor resistivity & $2.42 \mathrm{~m} \Omega / \mathrm{m} @ 20 \mathrm{C}$ \\
\hline Coil inner diameter (nominal) & $4 \mathrm{~cm}$ \\
\hline Coil outer diameter (nominal) & $22 \mathrm{~cm}$ \\
\hline Capacitor $\mathrm{C}_{1}$ & $10.03 \mathrm{mF}$ \\
\hline Capacitor $\mathrm{C}_{2}$ & $9.95 \mathrm{mF}$ \\
\hline Capacitor $\mathrm{C}_{3}$ & $10.37 \mathrm{mF}$ \\
\hline ESR max. & $20 \mathrm{~m} \Omega$ \\
\hline Thyristor $\mathrm{T}_{1}$ Vdrop & $0.83 \mathrm{~V}$ \\
\hline Thyristor $\mathrm{T}_{1}$ linear resistance & $1.60 \mathrm{~m} \Omega$ \\
\hline Diode $\mathrm{D}_{1}$ Vdrop & $1.10 \mathrm{~V}$ \\
\hline Diode $\mathrm{D}_{1}$ linear resistance & $3.71 \mathrm{~m} \Omega$ \\
\hline Connection leads resistance & $2.98 \mathrm{~m} \Omega$ \\
\hline Connection leads inductance & $1.0 \mu \mathrm{H}$ \\
\hline Coil leads outs resistance & $1.13 \mathrm{~m} \Omega$ \\
\hline
\end{tabular}

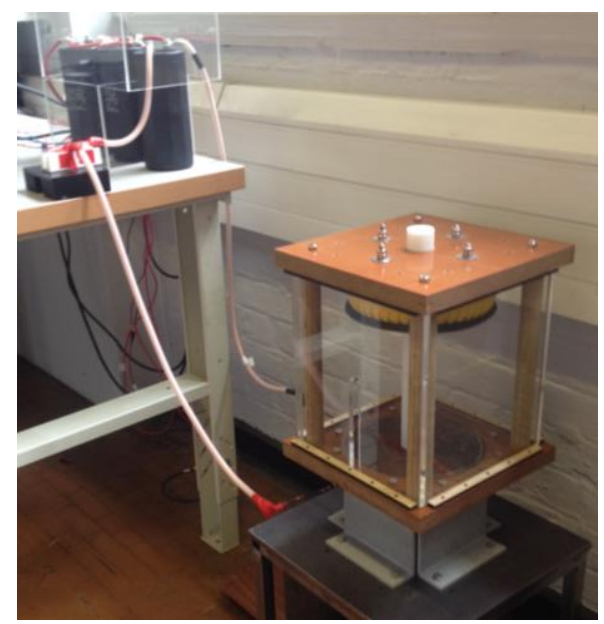

Fig. 3. TC test-rig

\section{B. FE Model}

Based on the parameters in Table I a 2D axis-symmetric FE model was implemented using COMSOL 5.2 multi-physics software. Although not strictly axis-symmetric this assumption about the coil geometry has been commonly used in the research literature for the modelling and analysis of the TC using FEA software [14-17]. COMSOL magnetic fields, solid mechanics and electrical circuit interfaces are used in the model implementation. In the multi-physics implementation a lumped representation of the excitation circuit was interfaced with a FE representation of the coil centered in a large air domain. FE and electric circuit equations were solved simultaneously using a fully coupled solver. In the 2D FE model each turn of the coil is considered separately and represented by an array of contiguous circles in the model 
geometry, where the armature is shown as a rectangular region above the coil turns (Fig. 1 right). The armature mechanical behavior was modeled using COMSOL solid mechanics interface, where isotropic linear elastic material is assumed. The force acting over the armature was calculated within the mechanics interface as the combination of Lorentz force contribution and gravity effects. For the armatures considered in this work the effect of aerodynamic drag is minimal and was neglected in the model. For larger surface armatures with complicated geometry the drag force may become relevant and should be considered. A deformable moving mesh was used to accurately account for armature displacement. Equations (1)-(7) are used for the FEA software for the model solution, the corresponding variables are listed in Table II, vector variables are identified with the symbol $\rightarrow$.

$$
\begin{array}{r}
\sigma_{e} \frac{\partial \vec{A}}{\partial t}-\sigma_{e} \vec{v} \times \vec{B}+\vec{J}=\vec{J}_{e} \\
\vec{\nabla} \times \vec{A}=\vec{B} \\
\vec{\nabla} \times \vec{H}=\vec{J} \\
\vec{J} \times \vec{B}=\vec{F}_{l} \\
\rho \frac{\partial^{2} u}{\partial t^{2}}-\vec{\nabla} \cdot \vec{S}=F \\
\sigma_{e 0}\left[1+\alpha\left(T-T_{0}\right)\right]^{-1}=\sigma_{e} \\
\rho C_{p}\left(\frac{\partial T}{\partial t}+\vec{v} \cdot \vec{\nabla} T\right)=\vec{\nabla} \cdot(k \vec{\nabla} T)+Q
\end{array}
$$

TABLE II

FEA SOFTWARE EQUATIONS VARIABLES

\begin{tabular}{|l|l|}
\hline Variable & Description \\
\hline$\vec{B}$ & Magnetic flux density \\
\hline$\vec{H}$ & Magnetic field intensity \\
\hline$\vec{J}$ & Current density \\
\hline$\vec{J}_{e}$ & External current density \\
\hline$\vec{A}$ & Magnetic vector potential \\
\hline$\vec{F}_{l}$ & Lorentz force \\
\hline$\vec{v}$ & Velocity \\
\hline$\vec{S}$ & Stress tensor \\
\hline$\sigma_{e}$ & Electric conductivity \\
\hline$\sigma_{e} 0$ & Reference electric conductivity \\
\hline$T$ & Temperature \\
\hline$T_{0}$ & Reference temperature \\
\hline$\alpha$ & Temperature coefficient \\
\hline$\rho$ & Density of the material \\
\hline$u$ & Displacement \\
\hline$F$ & Force acting over the solid \\
\hline$C_{p}$ & Heat capacity \\
\hline$k$ & Thermal conductivity \\
\hline$Q$ & Resistive losses \\
\hline
\end{tabular}

The mean armature velocity was calculated with (8) using the total kinetic energy $\left(W_{k}\right)$ reported by the FE software.

$$
v=\sqrt{\frac{2 W_{k}}{m}} \quad \mathrm{~m} / \mathrm{s}
$$

where $m$ is armature mass. $W_{k}$ is automatically calculated and results from the integral of the kinetic energy density over the solid domains. Given that the only solid domain in movement in the simulations is the armature, $W_{k}$ represents the armature's kinetic energy.
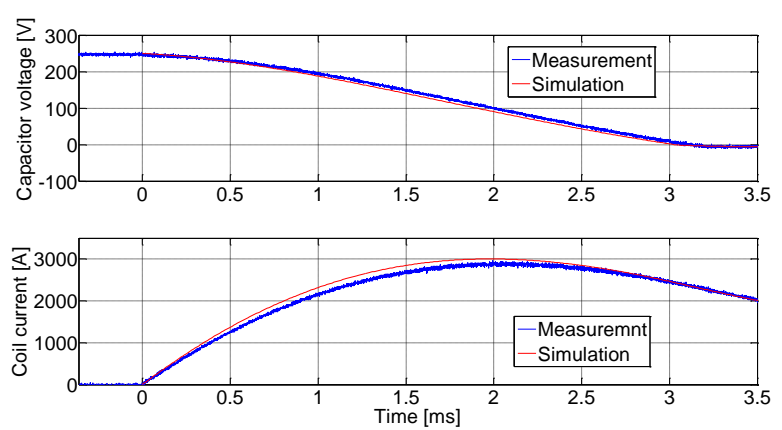

Fig. 4. Coil current and capacitor voltage comparison between measurements and 2D FE model.

\section{EXPERIMENTAL VALIDATION}

In order to assess the accuracy of the TC 2D FE axissymmetric model, simulation results were compared against experimental measurements. In the scenarios considered in this assessment the armature moves in the vertical direction. Therefore, a rectangular air domain with a width and height of three and six times the coil outer radius, respectively, was used on the 2D FE model implementation; with the coil placed in the center of the air domain. A fine physicscontrolled triangular mesh, with a minimum element size of $0.075 \mathrm{~mm}$, was applied to coil and air domains. The air domain was bounded by a homogeneous Dirichlet BC. For simplicity the coil response with no armature was first measured in the TC rig. In this test, coil current and capacitor bank voltage were measured using a CWT Rogowski coil and a differential voltage probe. Fig. 4 shows the coil current and capacitor bank voltage for a simulation, obtained using COMSOL circuits interface, and an experimental result. As can be seen in Fig. 4 the simulation results differ from the experimental measurements. Since all the electric circuit parameters (besides coil values) are known from Table I, differences between simulation and experimental results are most probably related to the FE part of the simulation. Factors such as meshing, BCs, solution settings and geometric discrepancies may explain the difference. The limitations of the TC 2D FE axis-symmetric representation are assessed in detail below.

\section{A. Axis-symmetric coil model error assessment}

To assess the accuracy of the 2D model predicted coil parameters against existing alternatives, the estimated coil inductance and resistance values were compared with those obtained from measurements, a 3D FE stationary solution and analytical expressions. It should be noted that given the approximate nature of a FE solution the predicted values are susceptible to model implementation and solution settings (e.g. domain geometry, mesh density, boundary conditions, tolerance error). For instance, the size of the air domain and boundary conditions (BCs) have a marked effect on the calculated inductance value, while mesh density affects the predicted coil resistance; i.e. a larger air domain improves the accuracy of the predicted inductance value while a denser mesh is beneficial for coil resistance calculation.

In this analysis the 3D FE model was only used to estimate 
coil parameters, therefore, for economy of computing resources, the coil was placed in the center of a spherical air domain with a radius three times the coil outer radius. A custom tetrahedral mesh was applied to the FE model to minimize RAM requirements. The 3D spherical air domain was set as three times the coil outer diameter, since differences in calculated inductance values for further diameter increases were negligible. An infinite element domain, with a thickness of a quarter of the sphere radius, was included as the sphere outermost layer. The presence of the infinite element domain forces the FE software to stretch the coordinates within the domain, emulating an infinitely large domain (which is beneficial for coil inductance calculation) without increasing the actual domain size, thus reducing the impact that the $\mathrm{BC}$ has on the calculated inductance value. The same BC type was used in both 2D and 3D models. Since the 2D model cannot include the coil lead outs, these were neglected in the 3D model in order to enable a straight forward comparison between FE implementations.

Although the 3D stationary model takes a fraction of the time required to solve the $3 \mathrm{D}$ transient simulation, the stationary 3D solution still requires considerable computer resources and cpu time to be completed, see section IV-B. As an alternative to the $3 \mathrm{D}$ simulation, and for comparison, an analytical expression was used for coil inductance calculation [18-20]. Wheeler's empirical formula for planar coil inductance calculation (9) was used here for comparison.

$$
L=\frac{n^{2} a^{2}}{(8 a+11 c)} \mu \mathrm{H}
$$

where $n$ is the number of turns, $a$ is the coil mean radius, and $c$ is the coil width in inches. It should be realized that many formulae for calculation of planar coil inductance rely on simplifications and approximations that limit their applicability to certain conductor cross section geometries [19]. However if suitable geometries are considered, accuracy within $5 \%$ of measured values can be expected using (9). The accuracy will be lower if for instance: there are few turns, the spacing between turns is high, or if skin effect and distributed capacitance are important factors [19]. For completeness, theoretical DC coil resistance is also included in the comparison. Theoretical coil resistance was calculated by multiplying the coil length $(11.45 \mathrm{~m})$, obtained using a CAD software program, by the wire manufacturer $\Omega / \mathrm{m}$ value at $20^{\circ} \mathrm{C}$. Table III summarizes coil inductance and resistance values obtained from the two FE implementations, compared with the analytically calculated and measured values. It should be noted that, contrary to the $\mathrm{FE}$ and analytical values, measurement quantities in Table III include coil lead out effects; spiral coil and lead outs form a single continuous piece of wire. When lead outs were included in the 3D model their effect on coil inductance was negligible. On the other hand, the resistance of the 3D model with lead outs included was calculated as $29.02 \mathrm{~m} \Omega$, slightly higher than the theoretical coil resistance value of $28.84 \mathrm{~m} \Omega$ and higher than the measured value of $28.77 \mathrm{~m} \Omega$. This difference is probably related to discrepancies between the model and the actual coil in the regions where the coil lead outs bend (see Fig. 1 left).
Nevertheless, good agreement between the 3D model predicted values and measurements exists. For instance, the relative error in inductance for the 3D FE simulation, compared with the measured value, is $2.2 \%$ while for the analytical expression it is $2.8 \%$. In contrast the $2 \mathrm{D}$ simulation exhibits a higher error in inductance of $12 \%$. However, as noted before, in an FE simulation the model settings may have an important effect on the simulation results. For instance, when an air domain similar in size and geometry to that used in the 3D model was considered in the 2D implementation the difference in predicted inductance values between models reduced significantly, although it still remained large as illustrated in Fig. 5. Fig. 5 shows the absolute and relative resistance and inductance differences of the 2D model compared to the 3D model for several coil turn numbers when using similar air domain settings and BCs. In this exercise the radius of the spherical air domain region was increased to four times the coil outer radius to compare the models under most favorable conditions. The coil outer radius was dictated by the number of turns while all other coil parameters were left unchanged with respect to the previous case. Coil lead outs effects were not considered in the comparisons.

As can be seen in Fig. 5 the absolute difference between the $2 \mathrm{D}$ and $3 \mathrm{D}$ model calculated values for resistance and inductance increases as the turn number increases, and the relative difference increases with turn number for resistance while it decreases for inductance. Thus, under similar conditions the 3D FE model should be expected to be more accurate for coil parameter prediction than the 2D model. For example, even with the improvement in accuracy for the 28 turns coil predicted inductance value, the relative error in inductance of the 2D model is $6 \%$ of the measured value. In contrast that of the $3 \mathrm{D}$ model was reduced to $1.5 \%$. It should be noted that no significant further improvement in predicted inductance value was achieved in both models by increasing further the surrounding air domain size.

In published results differences in coil response have been attributed to stray inductance and resistance due to coil terminal effects not accounted for in the simulations; subsequent experimental results have been used to adjust the FE model response [14, 17]. In contrast the analysis in this paper suggests that the simplistic assumption of coil axial symmetry can be in itself a considerable source of error. A 3D model offers a more realistic representation of the physical device, however, since coil resistance and inductance are susceptible to mesh density and domain size the computing resources required for the $3 \mathrm{D}$ stationary analysis may become significant. Theoretical coil resistance and analytically predicted inductance (if applicable) can provide adequate reference values if the available computer resources for the $3 \mathrm{D}$ analysis are limited.

TABLE III

COIL INDUCTANCE AND RESISTANCE VALUES COMPARISON

\begin{tabular}{|l|l|l|}
\hline Source & Inductance $(\boldsymbol{\mu H})$ & Resistance $(\mathbf{m} \boldsymbol{\Omega})$ \\
\hline 2D FE (stationary) & 78.25 & 27.06 \\
\hline 3D FE (stationary) & 87.31 & 27.71 \\
\hline Analytical & 86.72 & 27.71 \\
\hline Measurement & 89.24 & 28.77 \\
\hline
\end{tabular}




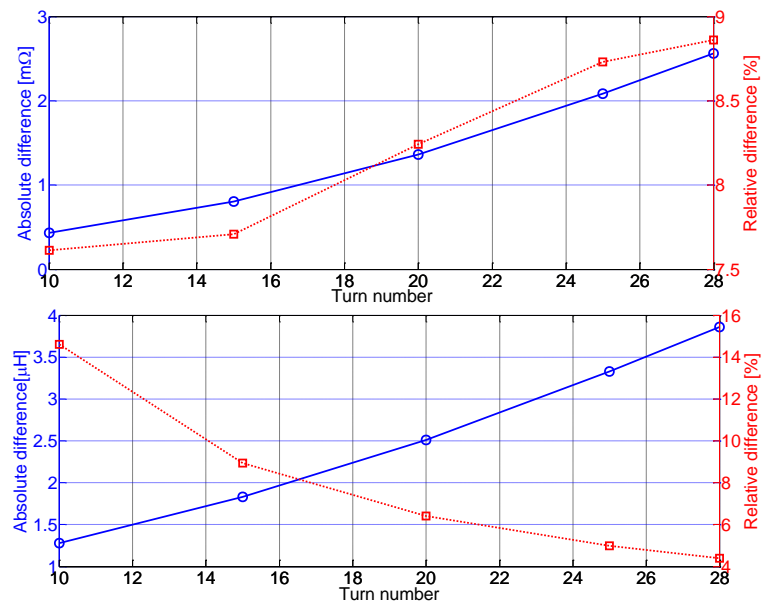

Fig. 5. Resistance (top) and inductance (bottom) differences of the 2D model compared with the 3D FE model for different coil turn number.

It is clear from this comparison that the 2D axial model significantly lacks in accuracy compared with the 3D model, thus any subsequent analysis using the $2 \mathrm{D}$ model must be taken with reserve. On the other hand, a full 3D FE transient simulation may be expensive in terms of computational resources, see section IV-B. Therefore a more faithful $2 \mathrm{D}$ implementation would be preferred for transient analysis.

In order to improve $2 \mathrm{D}$ model accuracy with respect to measured values, model passive compensation is investigated here as an alternative to a full 3D FE transient simulation. The 2D model is compensated by adding series resistance and inductance to account for differences between the 2D and 3D model predicted values. This approach is feasible due to the linear nature of the magnetic circuit. Given the dependence of the FE solution on model setup it is important to keep the 2D model consistent between simulations, once the degree of compensation has been established. The validity of this approach is investigated in the next section.

\section{B. Compensated 2D FE axis-symmetric model validation}

Fig. 6 shows the coil current and capacitor bank voltage for the same case as in Fig. 4, but this time the comparison is against the compensated model. As can be seen in Fig. 6 there is excellent agreement between the compensated model and the experimental results, thus validating (for coil response only) the proposed approach. Next, the accuracy of the compensated model was investigated when armature interaction occurs. For ultra-fast applications, as in HVDC breakers, typical operation times are around $2 \mathrm{~ms}$ [1-4]. Hence the focus in this analysis lies within this time frame. To investigate armature interaction effects, the TC armature displacement was recorded using a Photron Fastcam SA-X2 high speed camera at 50,000 fps; covering a fixed visual area of $4 \times 3.5 \mathrm{~cm}$, approximately, at a resolution of $512 \times 432$ pixels. Consequently, armature tracking time will vary between tests depending on armature speed. Automatic video tracking software was used to determine the armature displacement versus time characteristic and armature speed was estimated by numerical differentiation of the armature displacement. It should be noted that numerical differentiation of experimental data is prone to sudden and large variations: discontinuities in the measured signal (e.g. due to poor video edge resolution) are perceived as large changes in its derivative. In order to reduce jitter in the speed signal the recorded armature displacement was first conditioned using a zero-lag running average algorithm, after which a smooth noise-robust numerical differentiator was used to calculate the armature speed. In the tests two armature material types were used: aluminum alloy 6082-T6 and high conductivity oxygen free copper. Nominal material values for electrical conductivity and density were used in the compensated 2D FE simulations. In order to reduce armature flexing in this initial assessment $100 \mathrm{~mm}$ diameter armatures with thicknesses greater than $5 \%$ of diameter were used. The armature dimensions are listed in Table IV. TC operation was investigated at voltage levels of 100, 150, 200 and 250V.

Fig. 7 shows a picture of the experimental apparatus and Fig. 8 shows an example frame of the recorded armature displacement. A comparison between the measured and predicted coil current and armature velocity for the TC operating with the aluminum armature at an initial voltage of $250 \mathrm{~V}$ is shown in Fig. 9. As can be observed in Fig. 9, excellent agreement exists between predicted and measured values. A similar level of agreement occurred with the copper armature. This is further illustrated in Fig. 10; where measured and predicted armature speed is compared for the two armatures and for the four different charging voltages. Owing to the fixed visual area of the high speed camera, the duration of the measured speed signal in the figure varies depending on armature speed. It is clear from the measurements and analysis, that the compensated 2D FE axial model is able to predict with high fidelity the TC behavior for highly rigid armatures, even at speeds higher than $10 \mathrm{~m} / \mathrm{s}$. However due to the extreme forces to which the armature is subject, armature bending may occur. Moving mass minimization is one recommended technique for efficient TC operation [14-16]. Armature mass reduction may help to gain speed at the cost of armature rigidity and bending, which if extreme may damage the actuator armature. The ability of the 2D FE model to predict TC behavior when moderate armature bending occurs is investigated in the next section.
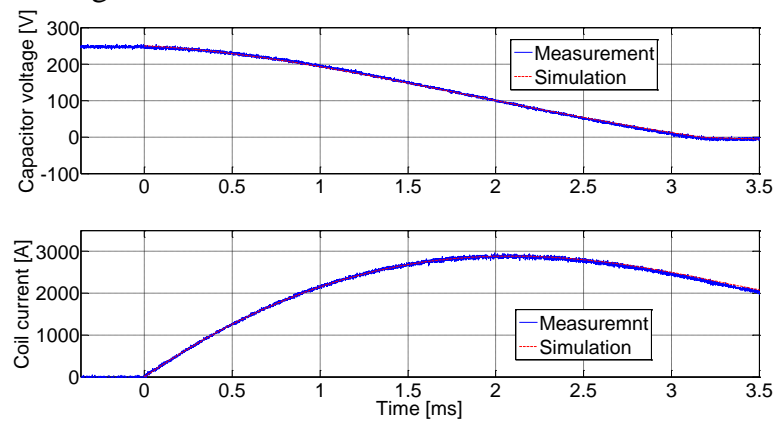

Fig. 6. Coil current and capacitor voltage comparison between measurements and 2D FE model with compensation.

TABLE IV

ARMATURES DIMENSIONS

\begin{tabular}{|l|l|l|l|}
\hline \multicolumn{1}{|c|}{ Material } & \multicolumn{1}{|c|}{$\begin{array}{c}\text { Thickness } \\
{[\mathbf{m m}]}\end{array}$} & $\begin{array}{c}\text { Inner radius } \\
{[\mathbf{m m}]}\end{array}$ & $\begin{array}{c}\text { Outer radius } \\
{[\mathbf{m m}]}\end{array}$ \\
\hline Copper & 6.36 & 20 & 50 \\
\hline Al 6082-T6 & 5.98 & 20 & 50 \\
\hline
\end{tabular}




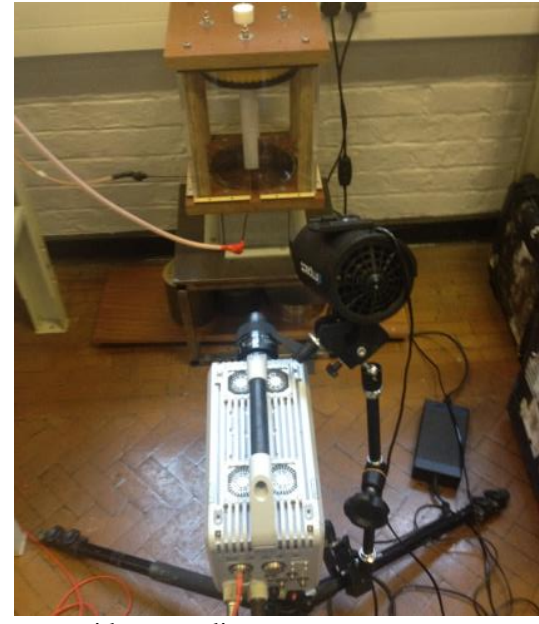

Fig. 7. TC prototype video recording arrangement

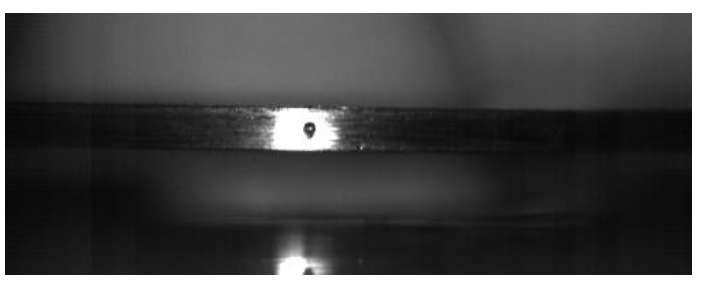

Fig. 8. High speed camera video frame

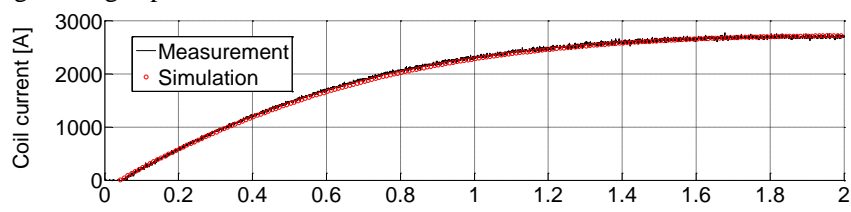

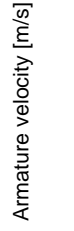

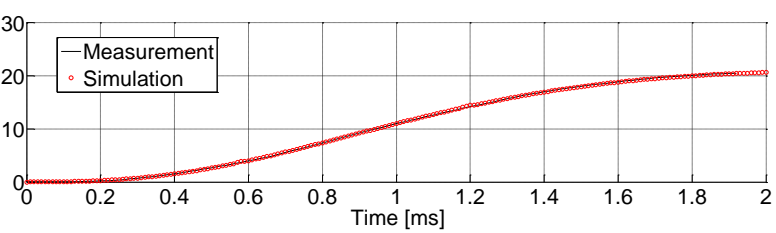

Fig. 9. Experimental vs. predicted coil current (top) and armature velocity (bottom) for a small 6mm thick $\mathrm{Al}$ 6082-T6 armature.
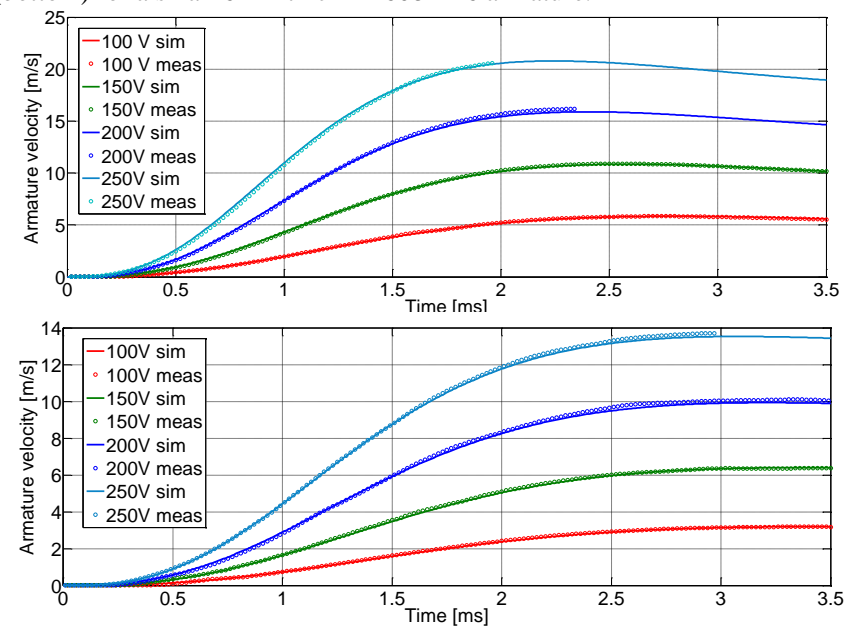

Fig. 10. Measurement versus simulation speed comparison for aluminum (top) and copper (bottom) armatures for different capacitor bank voltages.

\section{MODEL ASSESSMENT FOR ARMATURE FLEXING}

With the assumed geometry a 2D FE axis-symmetric model is limited in its capability to predict armature vibration modes, and therefore the effects of armature bending in the armature's velocity signal. The impact of armature bending in the predicted armature velocity is investigated in this section.

\section{A. Frequency domain analysis}

Limitations of the 2D FE model for the prediction of armature flexing are illustrated in Figs. 11-12, where vibration modes predicted by 3D and 2D FE eigen frequency analysis, are shown. A $3 \mathrm{~mm}$ thick, $4 \mathrm{~cm}$ inner diameter, $22 \mathrm{~cm}$ outer diameter, aluminum alloy 6082-T6 armature disc was modelled for the analysis. The vibration modes shown in Fig. 11 are a subset of the modes below $2 \mathrm{kHz}$ predicted by the 3D eigen frequency analysis. In contrast, the first vibration mode in Fig. 12 (fundamental mode) was the only mode below 2 $\mathrm{kHz}$ that was predicted by the $2 \mathrm{D}$ axial model. This limitation highlights one of the drawbacks of the 2D model.

Higher frequency modes usually recede faster with time than low frequency modes. Hence, low frequency modes are expected to be more relevant on the armature mechanical behavior. Nevertheless, in order to verify the correctness of the FE model predictions six disc armatures of different material grades and thickness were tested and their mechanical and electrical properties determined. All the tested disc armatures possess inner and outer diameters of 4 and $22 \mathrm{~cm}$, respectively. Material density was approximated using the armature weights and geometric dimensions, assuming $1 \mathrm{~kg}$ of weight mirrors $1 \mathrm{~kg}$ of mass. To determine the armature material electrical conductivity a sample of known cross section and length was connected to a high precision micro ohm meter through two high conductivity electrodes of known contact resistance, Fig. 13. The material sample resistance was measured and its material conductivity calculated.

Table V summarizes the measured armature properties. For convenience the different armatures will be referred to, from here onwards, by their rounded thickness value: 3,6 and $9 \mathrm{~mm}$, accordingly. It is important to mention that given its low thickness and rigidity it was impossible to determine with accuracy the conductivity of the aluminum alloy used in the $3 \mathrm{~mm}$ armature. When pressure was applied to the electrodes to ensure good electrical contact the sample bar tended to bend, resulting in considerable variations in measured resistance, mostly due to varying contact resistance. Consequently this armature will be omitted in most of the subsequent analysis.

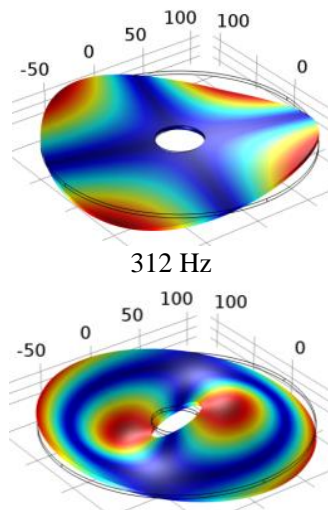

$1214 \mathrm{~Hz}$

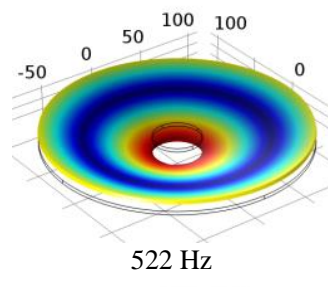

$50100 \quad 100$

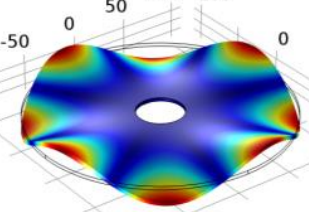

$1315 \mathrm{~Hz}$
Fig. 11. 3D FE eigen frequency analysis, $3 \mathrm{~mm}$ aluminum armature predicted shape modes below $2 \mathrm{kHz}$. 

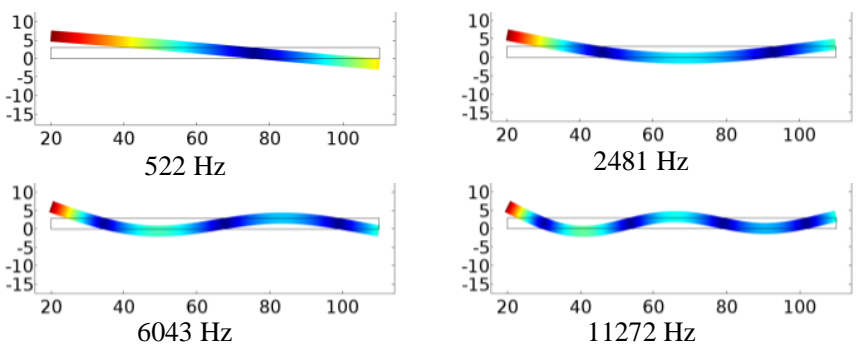

Fig. 12. 2D FE eigen frequency analysis, $3 \mathrm{~mm}$ aluminum armature predicted shape modes up to $12 \mathrm{kHz}$.

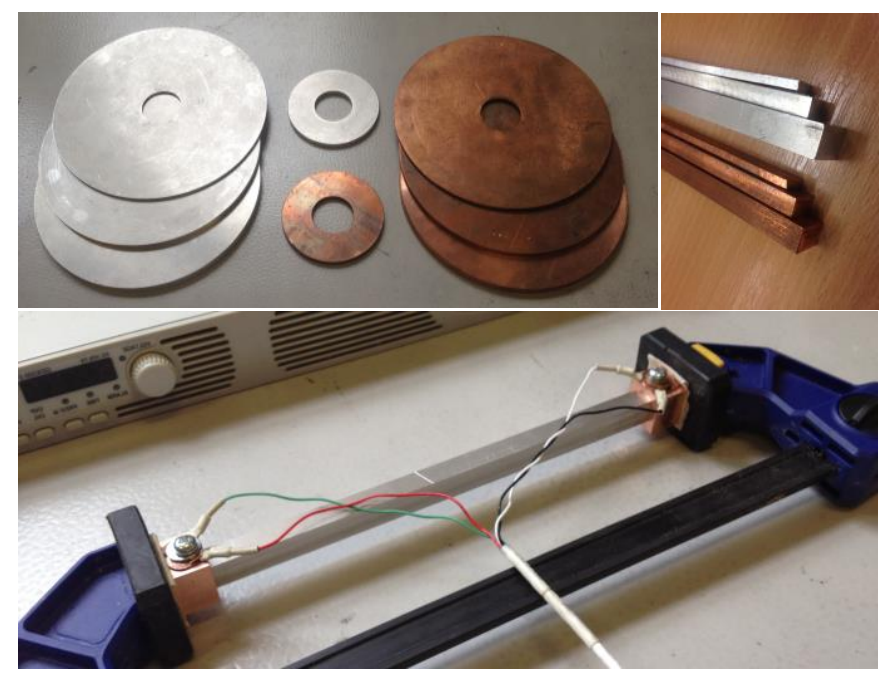

Fig. 13. Armatures (top left), material samples (top right) and resistance measurement (bottom).

TABLE V

ARMATURES MEASURED PROPERTIES

\begin{tabular}{|l|c|c|c|c|}
\hline $\begin{array}{c}\text { Armature } \\
\text { Material }\end{array}$ & $\begin{array}{c}\text { Thickness } \\
{[\mathrm{mm}]}\end{array}$ & $\begin{array}{c}\text { Weight } \\
{[\mathrm{g}]}\end{array}$ & $\begin{array}{c}\text { Density } \\
{\left[\mathrm{kg} / \mathrm{m}^{3}\right]}\end{array}$ & $\begin{array}{c}\text { Conductivity } \\
{[\% \text { IACS }]}\end{array}$ \\
\hline $\mathrm{Cu}$ & 3.28 & 1070 & 8845 & 83 \\
\hline $\mathrm{Cu}$ & 6.36 & 2063 & 8828 & 85 \\
\hline $\mathrm{Cu}$ & 9.00 & 2906 & 8811 & 65 \\
\hline $\mathrm{Al}$ & 2.89 & 283 & 2664 & -- \\
\hline $\mathrm{Al}$ & 5.98 & 595 & 2706 & 36 \\
\hline $\mathrm{Al}$ & 9.07 & 888 & 2664 & 25 \\
\hline
\end{tabular}

Vibration frequencies of annular circular plates can be analytically calculated using (10) [21].

$$
f=\frac{\beta}{2 \pi r^{2}} \sqrt{\frac{D}{\rho t}}
$$

with

$$
D=\frac{E t^{3}}{12\left(1-\mu^{2}\right)}
$$

where $r$ is the armature radius, $t$ is disc thickness, $E$ is Young's modulus, $\mu$ is Poisson's ratio and $\beta$ is a coefficient that varies depending on mode shape, Poisson's ratio and plate internal and external radii. For a free-free annular plate, with an inner to outer diameter ratio of 0.18 with $\mu=0.33, \beta \approx 8.50$ for the fundamental shape mode $(1,0)$, [22]. For validation purposes the analytical frequency value for the fundamental mode obtained using (10) will be compared with that predicted by $2 \mathrm{D}$ and $3 \mathrm{D} \mathrm{FE}$ simulations and that obtained from experimental measurements (M).
In order to determine experimentally the armatures' natural frequencies, they were subjected to an impact test. In each test a Bruel\&Kjær type DT4394 miniature piezoelectric accelerometer was mounted perpendicular to the armature main surface, Fig. 14, and the armature was mechanically excited using an impact hammer. The accelerometer output signal was conditioned and recorded using a Bruel\&Kjær 3560-B-130DAQ system and the Pulse Vibration Analysis platform. A vibration signal FFT analysis was performed using the Pulse platform proprietary routine, at 6400 line resolution, for a $0-2 \mathrm{kHz}$ bandwidth. Exponential FFT averaging was used to reduce signal noise. Fig 15 shows the resulting vibration frequency spectrum for the $9 \mathrm{~mm}$ copper armature, as an example.

Tables VI and VII compare the eigen frequencies predicted by the $2 \mathrm{D}$ and $3 \mathrm{D}$ FE models against the measured natural frequencies for the copper and aluminum armatures for frequencies below $2 \mathrm{kHz}$. To be consistent with the theoretical analysis, a Poisson's ratio of 0.33 was assumed for all armatures in the FE eigen frequency analysis. Young's modulus was adjusted for each disc to better match globally the measured frequencies. In the tables the fundamental frequency, obtained with (10), is listed in the corresponding column header as reference. Predicted and measured frequencies of similar value are listed in the same row for each armature. An empty cell indicates that no similar component was found for the armature within the corresponding set of predicted or measured frequencies. The presence of duplicated frequencies in the tables implies the existence of predicted vibration modes of similar shape but displaced in phase.

From the results in Tables VI and VII it is clear that the 3D FE model is able to predict with good accuracy the expected mechanical response of the armature. On the other hand, below $2 \mathrm{kHz}$, the $2 \mathrm{D}$ model only predicted the existence of the fundamental vibration mode. It is interesting to note that not all frequencies predicted by the 3D model were detected in the physical system. It is also interesting to see how the number of natural frequencies below $2 \mathrm{kHz}$ decrease with armature thickness (rigidity), pushing the fundamental vibration mode to a higher frequency, as can be predicted with (10).

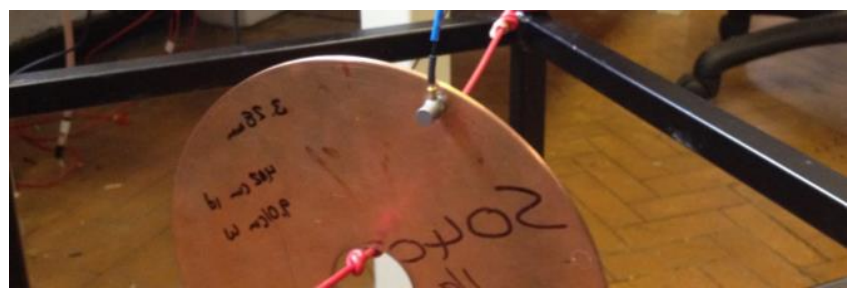

Fig. 14. Accelerometer mounting for armature impact test.

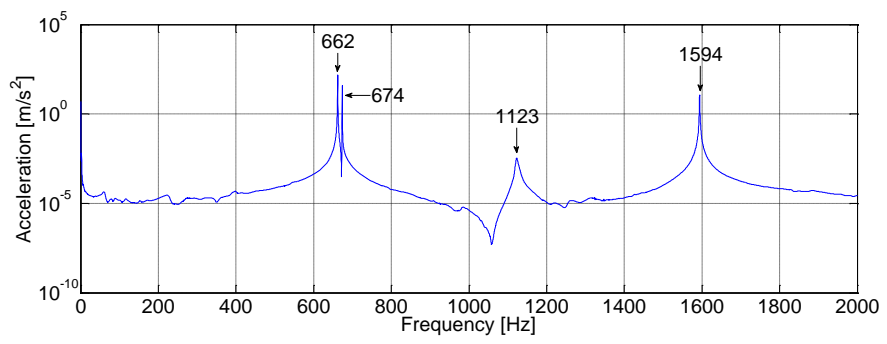

Fig. 15. $9 \mathrm{~mm}$ Copper armature impact test vibration frequency spectrum. 
TABLE VI COPPER ARMATURES

PREDICTED VS MEASURED NATURAL FREQUENCIES BELOW $2 \mathrm{KHZ}$

\begin{tabular}{|c|c|c|c|c|c|c|c|c|}
\hline \multicolumn{3}{|c|}{$3 \mathrm{~mm}$, fund $=404 \mathrm{~Hz}$} & \multicolumn{3}{|c|}{$6 \mathrm{~mm}$, fund=789 $\mathrm{Hz}$} & \multicolumn{3}{|c|}{ 9mm, fund $=1121 \mathrm{~Hz}$} \\
\hline 2D & $\mathbf{M}$ & 3D & 2D & $\mathbf{M}$ & 3D & 2D & $\mathbf{M}$ & 3D \\
\hline-- & 240 & 241 & -- & 468 & 468 & - & 662 & 662 \\
\hline-- & 245 & 241 & -- & - & 468 & - & 674 & 662 \\
\hline 404 & 434 & 404 & 784 & 807 & 784 & 1110 & 1123 & 1110 \\
\hline-- & 580 & 579 & -- & 1119 & 1118 & - & 1594 & 1576 \\
\hline-- & - & 579 & -- & - & 1118 & - & - & 1576 \\
\hline-- & -- & 939 & -- & - & 1804 & & & \\
\hline-- & - & 939 & -- & - & 1804 & & & \\
\hline-- & 1022 & 1017 & -- & 1960 & 1957 & & & \\
\hline-- & - & 1017 & & & & & & \\
\hline-- & 1566 & 1558 & & & & & & \\
\hline-- & -- & 1558 & & & & & & \\
\hline-- & -- & 1622 & & & & & & \\
\hline-- & -- & 1622 & & & & & & \\
\hline-- & -- & 1920 & & & & & & \\
\hline
\end{tabular}

TABLE VII ALUMINUM ARMATURES

PREDICTED VS MEASURED NATURAL FREQUENCIES BELOW $2 \mathrm{KHZ}$

\begin{tabular}{|c|c|c|c|c|c|c|c|c|}
\hline \multicolumn{3}{|c|}{$3 \mathrm{~mm}$, fund=513 Hz } & \multicolumn{3}{|c|}{$6 \mathrm{~mm}$, fund $=1040 \mathrm{~Hz}$} & \multicolumn{3}{|c|}{$9 \mathrm{~mm}$, fund $=1589 \mathrm{~Hz}$} \\
\hline $2 \mathrm{D}$ & $\mathbf{M}$ & 3D & $2 D$ & $\mathbf{M}$ & 3D & $2 D$ & $\mathbf{M}$ & 3D \\
\hline-- & 325 & 307 & -- & 615 & 618 & -- & 936 & 938 \\
\hline-- & 336 & 307 & -- & 623 & 618 & -- & 946 & 938 \\
\hline 513 & 525 & 513 & 1035 & 1048 & 1035 & 1574 & 1589 & 1574 \\
\hline-- & 731 & 735 & -- & 1463 & 1477 & & & \\
\hline-- & -- & 735 & -- & -- & 1477 & & & \\
\hline-- & - & 1194 & & & & & & \\
\hline-- & - & 1194 & & & & & & \\
\hline-- & 1263 & 1293 & & & & & & \\
\hline-- & 1292 & 1293 & & & & & & \\
\hline-- & 1953 & 1982 & & & & & & \\
\hline-- & 1992 & 1982 & & & & & & \\
\hline
\end{tabular}

\section{B. Time-domain analysis}

Since armature bending occurs, not all the parts in the armature move at the same speed. This is illustrated in Fig. 16, where armature displacement is modelled using the 2D FE simulation for the $3 \mathrm{~mm}$ copper armature; armature bending is exaggerated in the figure for illustration purposes. Thus for a correct comparison, the measured speed needs to be compared against the predicted speed of a point located in a similar position to the tracked feature. Such a comparison is shown in Fig. 17, where the measured speed is compared to the relative speed of a point located on the external armature edge of the compensated FE model, the armature mean speed is included in the figure for reference.

The results in Fig. 17 show that when simulations and measurements focus on a similarly located point the 2D model is able to predict with excellent accuracy the armature behavior, even when armature bending occurs. Thus implying that the fundamental vibration mode is the dominant one and, most importantly, that the predicted mean armature velocity is correct. Furthermore, it was found during the analysis that if sensible values of Young's modulus (around $115 \mathrm{GPa}$ for copper and $70 \mathrm{GPa}$ for aluminum alloys) and Poisson's ratio (0.30-0.33 for both types of base material) are used, small variations in their values do not impact significantly on the model predictions. On the other hand the numerical simulation was found to be quite sensitive to the material electrical conductivity. Electrical conductivity affects mean armature velocity.

To verify frequency dominance a joint time-frequency analysis of the armature's velocity signal was conducted. The analysis is complicated by the short duration of the recorded signal and its non-stationary nature. Due to its robust capabilities for the analysis of non-stationary signals the highly adaptive Hilbert-Huang transform (HHT) algorithm [23] was chosen for signal processing. Fig. 18 shows the timefrequency plot of the armature velocity signal obtained using the HHT algorithm for a $0-2 \mathrm{kHz}$ bandwidth for simulation and experimental results for the $9 \mathrm{~mm}$ copper armature, with an initial voltage of $150 \mathrm{~V}$. As can be expected, the experimental result exhibits a richer and less well defined spectrum than the simulation result, with a strong frequency component sitting around $1100 \mathrm{~Hz}$; which incidentally matches the armature's fundamental vibration mode frequency. Traces of a component around $1.5 \mathrm{kHz}$ are also visible in the spectrum of the experimental signal. In contrast, only the $1100 \mathrm{~Hz}$ component is visible for the simulation results in the higher part of the spectrum. It is interesting to notice in Fig. 18 that both spectrums exhibit a strong, non-predicted, low frequency component that falls below $100 \mathrm{~Hz}$ with time. Such a component is related to the armature mean speed. The components relatively high value at the beginning is most probably related to HHT end point effects [24]. It should be noted that for all the cases in Fig. 17, the presence of the fundamental vibration component was clearly visible in the corresponding velocity spectrum.

This analysis confirms that the fundamental vibration mode is the dominant mode for the investigated scenarios, and explains why the compensated 2D FE model is able to predict with good accuracy the experimental armature behavior. However, in accordance with the eigen frequency analysis above, inaccuracies in the 2D FE model prediction are to be expected. Thus, even though excellent agreement is shown between the 2D model results and experimental measurements for the illustrated cases, there will be situations where this will not occur. This is because, as shown in section IV-A, the 2D model cannot predict all possible armature mode shapes. For instance, for several frequencies in Tables VI and VII, two different vibration modes are predicted. These mode pairs are similar in shape, but displaced in phase, Fig 19. Thus depending on dominant vibration modes and location of the tracked feature, the predicted speed may not coincide in phase with the measured speed or may otherwise fail to predict vibration modes present in the physical armature. This scenario is illustrated in Fig. 20, where measured and predicted speed oscillations seem to be in phase opposition in Fig. 20a, while measured high frequency oscillations are not present in the simulation results of Fig. 20b. Interestingly, the behavior shown in Fig. 20 was not observed at higher armature speed. For higher capacitor voltage and for the same armature only the fundamental vibration mode was observed. Thus the type of vibration mode depends on system excitation. Nevertheless, the predicted speed remained close to the measured speed signal in all cases analyzed.

A 3D FE transient simulation is able to predict speed variations along the armature periphery. However, the considerable computer resources and simulation time that may be required by this type of simulation may make its use impractical at an early stage in the TC design process, if many 
simulations are necessary for design refinement. For example, in a Core i5 computer at $3.2 \mathrm{GHz}$ with $32 \mathrm{~GB}$ of RAM, the 28 turns 2D axis-symmetric model with a predefined physics controlled finer mesh was solved in an average of 40 minutes for a $3.5 \mathrm{~ms}$ simulation period. In contrast, a reduced 10 turns 3D transient model with an optimized user-controlled non deformable mesh took 125 hours to be solved on the same computer and for an identical simulation time. The 28 turn 3D transient case could not be processed due to insufficient RAM in the reference computer, owing to the large number of mesh elements required to represent the coil geometry with sufficient detail. The 28 turn 3D stationary solution took six hours to be completed. Clearly, for accurate fast FE analysis the 2D model with compensation represents an excellent compromise between results accuracy, computing resources and simulation speed.

\section{CONCLUSIONS}

In this paper the accuracy of a 2D TC axis-symmetric FE model with passive compensation is assessed by comparison with experimental results obtained from a purpose built TC test-rig. A 3D FE model was used to calculate more precise coil inductance values and the 2D model was compensated accordingly. Comparison with experimental results validated the proposed approach. It was found that analytical formulae may be used as an alternative for correct coil inductance calculation, when coil geometry allows it. It is shown that when no sizeable armature flexing occurs, detailed characterization of armature and excitation circuit allows for a high fidelity representation of the TC behavior. When armature bending occurs, the assumption of symmetry limits the 2D model capabilities. Shape modes naturally present in the TC armature may not be reflected correctly or are omitted altogether from the model predictions. However, the 2D model was able to predict with good accuracy the armature behavior for speeds in excess of $10 \mathrm{~m} / \mathrm{s}$ in the scenarios where the fundamental vibration mode was dominant. Good agreement between predicted mean velocity and measurements was observed for all the cases assessed. Correct armature electrical conductivity was found to be more relevant for accurate prediction of TC behavior than the material mechanical properties (Young's modulus and Poisson's ratio).

Given the important differences in computing time and computational resources that may be required for the solution of a 2D axis-symmetric model and those of a 3D FE transient model, the 2D FE axial model with compensation is an attractive alternative for fast and accurate analysis and design of ultra-fast TC actuators.

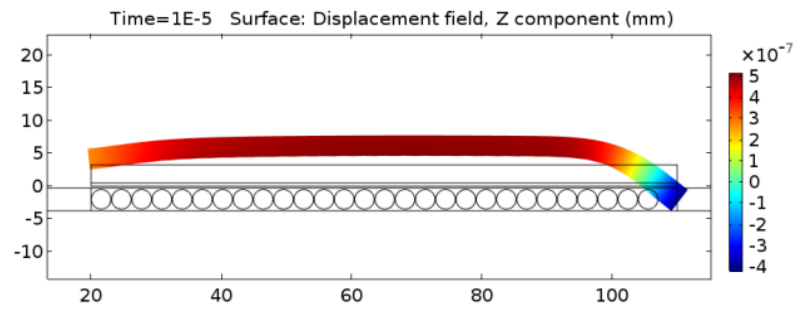

Fig. 16. FE simulation results for $3 \mathrm{~mm}$ copper armature at $250 \mathrm{~V}$, field displacement.
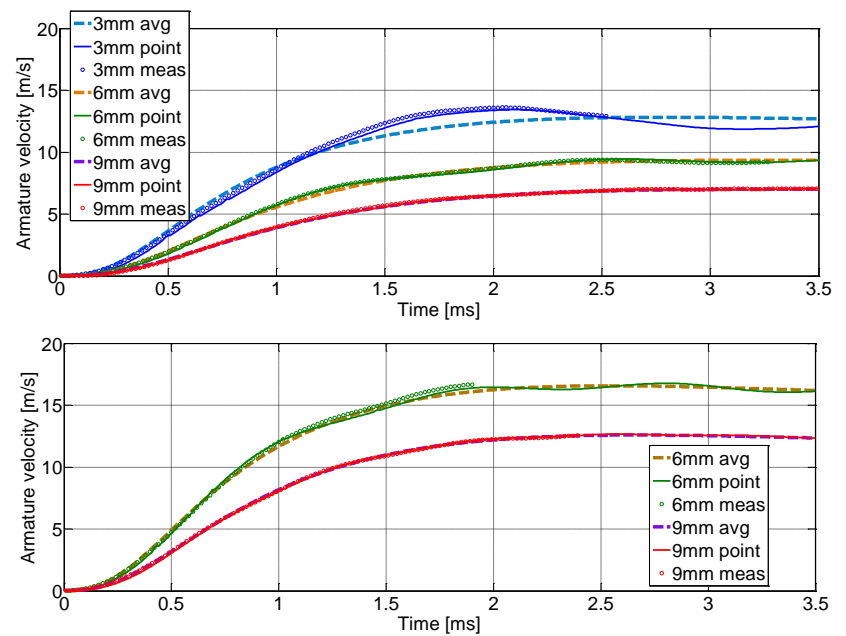

Fig. 17. Measured versus predicted speed for a point in the armature lateral edge for copper (top) and aluminum (bottom) armatures at $250 \mathrm{~V}$.
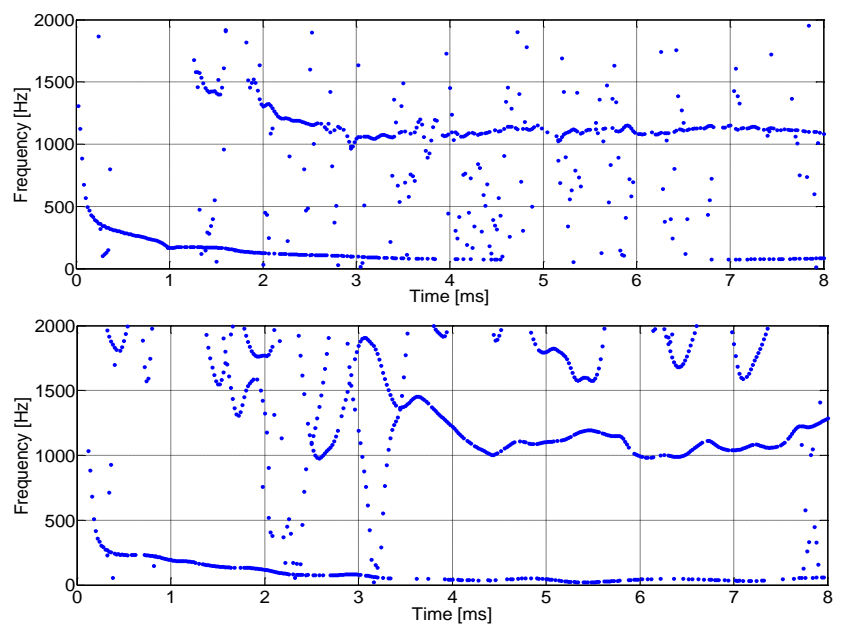

Fig. 18. Armature velocity instantaneous frequency for the $9 \mathrm{~mm}$ copper armature with $150 \mathrm{~V}$ excitation: simulation (top), experimental (bottom).
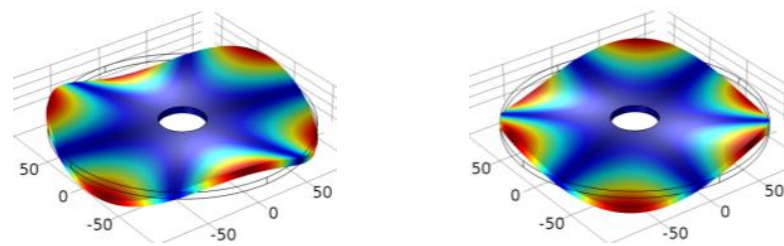

Fig. 19. Predicted shape modes at $1477 \mathrm{~Hz}$ for $6 \mathrm{~mm}$ aluminum armature.
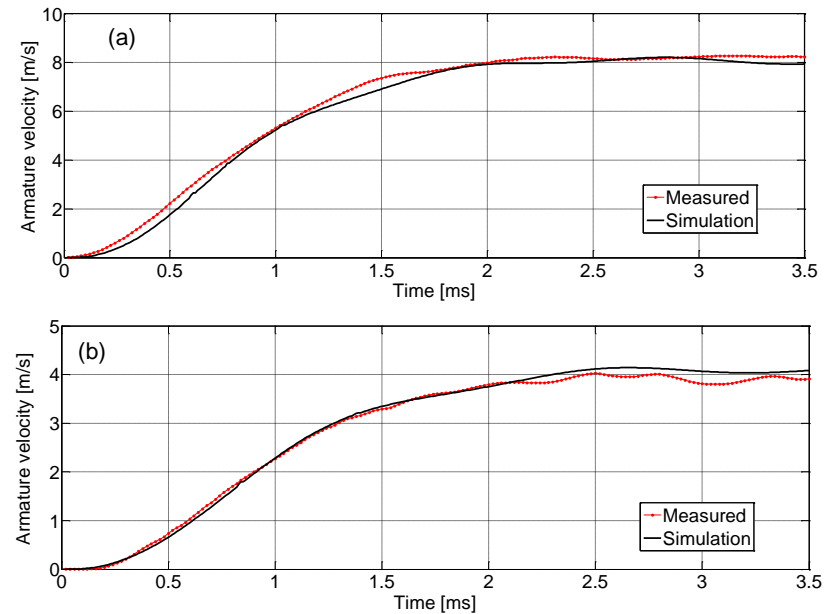

Fig. 20. Measured versus predicted speed for a point in the armature lateral edge for $6 \mathrm{~mm}$ aluminum (a) and copper (b) armatures at $150 \mathrm{~V}$. 


\section{REFERENCES}

[1] W. Holaus, K. Frohlich, "Ultra-fast switches- a new element for medium voltage fault current limiting switchgear," Power Engineering Society Winter Meeting, 2002. IEEE, vol.1, no., pp.299,304 vol.1, 2002

[2] M. Steurer, K. Frohlich, W. Holaus, and K. Kaltenegger, "A novel hybrid current-limiting circuit breaker for medium voltage: Principle and test results," IEEE Trans. Power Del., vol. 18, no. 2, pp. 460-467, Apr. 2003.

[3] W. Wen et al., "Research on Operating Mechanism for Ultra-Fast 40.5kV Vacuum Switches," in IEEE Transactions on Power Delivery, vol. 30, no. 6, pp. 2553-2560, Dec. 2015.

[4] J. Häfner, B. Jacobson, "Proactive Hybrid HVDC Breakers - A key innovation for reliable HVDC grids," (Cigré Bologna, Paper 0264, 2011)

[5] J. Magnusson, O. Hammar, G. Engdahl "Modelling and Experimental Assessment of Thomson Coil Actuator System for Ultra Fast Mechanical Switches for Commutation of Load Currents," International Conference on New Actuators and Drive Systems, Bremen, pp. 488-491, 14-16 Jun 2010.

[6] W. Li, Y. W. Jeong and C. S. Koh, "An Adaptive Equivalent Circuit Modeling Method for the Eddy Current-Driven Electromechanical System," in IEEE Transactions on Magnetics, vol. 46, no. 6, pp. 18591862 , June 2010.

[7] D. K. Lim et al., "Characteristic Analysis and Design of a Thomson Coil Actuator Using an Analytic Method and a Numerical Method," in IEEE Transactions on Magnetics, vol. 49, no. 12, pp. 5749-5755, Dec. 2013.

[8] W. Li, Z. Y. Ren, Y. W. Jeong and C. S. Koh, "Optimal Shape Design of a Thomson-Coil Actuator Utilizing Generalized Topology Optimization Based on Equivalent Circuit Method," in IEEE Transactions on Magnetics, vol. 47, no. 5, pp. 1246-1249, May 2011.

[9] M. T. Pham, Z. Ren, W. Li and C. S. Koh, "Optimal Design of a Thomson-Coil Actuator Utilizing a Mixed-Integer-Discrete-Continuous Variables Global Optimization Algorithm," in IEEE Transactions on Magnetics, vol. 47, no. 10, pp. 4163-4166, Oct. 2011.

[10] Y. Wu et al., "A New Thomson Coil Actuator: Principle and Analysis," in IEEE Transactions on Components, Packaging and Manufacturing Technology, vol. 5, no. 11, pp. 1644-1655, Nov. 2015.

[11] E. Dong, P. Tian, Y. Wang, and W. Liu, "The design and experimental analysis of high-speed switch in $1.14 \mathrm{kV}$ level based on novel repulsion actuator," in Electric Utility Deregulation and Restructuring and Power Technologies (DRPT), 2011 4th International Conference on,pp.767770, 6-9 July 2011.

[12] A. Bissal, J. Magnusson, G. Engdahl, "Comparison of Two Ultra-Fast Actuator Concepts," Magnetics, IEEE Transactions on, vol.48, no.11, pp.3315,3318, Nov. 2012

[13] V. Puumala, L. Kettunen, "Electromagnetic Design of Ultrafast Electromechanical Switches," Power Delivery, IEEE Transactions on, 2014.

[14] A. Bissal, E. Salinas, G. Engdahl, and M. Ohrstrom, "Simulation and verification of Thomson actuator systems," in Proc. COMSOL Conf., Paris, France, 2010, pp. 1-6.

[15] A. Bissal, J. Magnusson, G. Engdahl, "Electric to Mechanical Energy Conversion of Linear Ultrafast Electromechanical Actuators Based on Stroke Requirements," Industry Applications, IEEE Transactions on , vol.51, no.4, pp.3059,3067, July-Aug. 2015.

[16] D.S. Vilchis-Rodriguez, R. Shuttleworth, M. Barnes, "Finite element analysis and efficiency improvement of the Thomson coil actuator", 8th IET International Conference on Power Electronics, Machines and Drives (PEMD 2016), Glasgow, UK, pp. 1-6, 19-21 April 2016.

[17] C. Peng, I. Husain, A. Q. Huang, B. Lequesne and R. Briggs, "A Fast Mechanical Switch for Medium-Voltage Hybrid DC and AC Circuit Breakers," in IEEE Transactions on Industry Applications, vol. 52, no. 4, pp. 2911-2918, July-Aug. 2016.

[18] H.A. Wheeler, "Formulas For the Skin Effect", Proceedings of the I.R.E., pp. 412-424, Sept. 1942.

[19] H.A. Wheeler, "Simple Inductance Formulas for Radio Coils" Proceedings of the I.R.E., Vol. 16, no. 10, Oct. 1928.

[20] H. A. Wheeler, "Inductance formulas for circular and square coils," in Proceedings of the IEEE, vol. 70, no. 12, pp. 1449-1450, Dec. 1982.

[21] S. Timoshenko, D.H. Young, W.Weaver, "Vibration problems in engineering", John Wiley \& Son, $4^{\text {th }}$ edition, 1974.

[22] A.W. Leissa, "Vibration of plates", NASA SP-160 (1969).

[23] N. E. Huang, Z. Shen, S. R. Long, M. L. Wu, H. H. Shih, Q. Zheng, N. C. Yen, C. C. Tung, and H. H. Liu, "The empirical mode decomposition and Hilbert spectrum for nonlinear and non-stationary time series analysis," Proc. R. Soc. London A, vol. 454, pp. 903-995, 1998.

[24] N.E. Huang, "Hilbert-Huang Transform and its Applications," vol. 5, World Scientific (2005) pp. 18-24

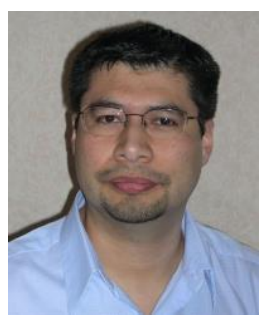

D. S. Vilchis-Rodriguez (M'10) received the Ph.D. degree in electrical engineering from the University of Glasgow, Glasgow, U.K., in 2010. He was a computer programmer and power quality consultant in Mexico for the period 1993-2004. He is currently a Research Associate with the Power \& Energy Division, University of Manchester, Manchester, U.K. His current research interests include electrical machines modelling, condition monitoring, power systems dynamics simulation and high voltage dc protection.

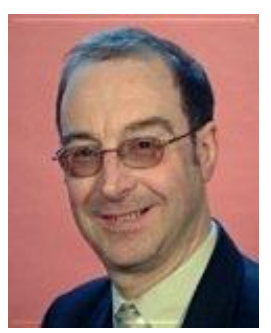

R. Shuttleworth (M'07) was born in the UK and completed his $\mathrm{BSc}$ and $\mathrm{PhD}$ degrees in Electrical and Electronic Engineering at The University of Manchester. He worked for a year at GEC Traction before joining the University as a lecturer in the Power System's Research group and later the Power Conversion Research group. He has around 100 papers and patents and was Director for the Power Electronics, Machines and Drives MSc course at Manchester University until 2016.

His main research activities are in the areas of Power Electronics, Energy Control and Conversion, HVDC, circuit breaking, and Energy Harvesting.

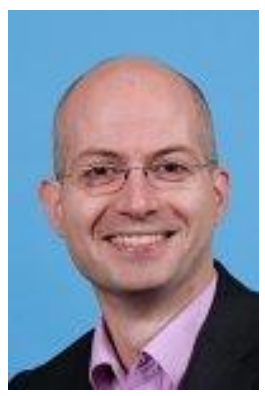

M. Barnes (M'96-SM'07) received the B.Eng. and Ph.D. degrees in power electronics and drives from the University of Warwick, Coventry, U.K., in 1993 and 1998, respectively. In 1997, he was a Lecturer with the University of Manchester Institute of Science and Technology, Manchester, U.K. (UMIST merged with The University of Manchester). He is currently Professor of Power Electronics Systems at The University of Manchester. His research interests cover the field of power-electronicsenabled power systems. 